\title{
Bovine Claw and Limb Disorders Related to Reproductive Performance and Production Diseases
}

\author{
Å. M. Sogstad, ${ }^{*} \dagger^{1}$ O. Østerås, ${ }^{*} \dagger$ and T. Fjeldaas ${ }^{*}$ \\ *Department of Production Animal Medicine, Norwegian School of Veterinary Science, 0033 Oslo, Norway \\ †Department of Norwegian Cattle Health Services, TINE Norwegian Dairies BA, 1431 Ås, Norway
}

\begin{abstract}
As part of a cross-sectional study of Norwegian Red Cattle, associations of lameness, lesions at the tarsus, claw shapes, and claw lesions with reproductive performance and production diseases were examined. Fiftyfive tiestall herds and 57 freestall herds were sampled by computerized systematic selection and 2,665 cows were trimmed and limb and claw disorders recorded by 13 specifically trained claw trimmers during the late winter and spring of 2002. After exclusions, 2,583 cows were included in this study. Most claw lesions were mild (score 1). Prevalence of moderate and severe lesions (score $2+3$ ) did not exceed $5 \%$ for any of the lesions. Hazard ratios for independent variables were identified using Cox regression analyses incorporating herd as a random effect in a positive stable frailty model. Wounds and swellings at the tarsus were associated with more clinical mastitis [hazard ratio $(\mathrm{HR})=$ 4.0 ] and teat injuries $(\mathrm{HR}=2.5)$. Moderate and severe heel-horn erosions in first-lactation cows were associated with increased calving interval $(\mathrm{HR}=0.60)$. Moderate and severe hemorrhages of the sole in first-lactation cows were associated with decreased interval from calving to first service $(\mathrm{HR}=1.6)$ and moderate and severe hemorrhages of the sole were associated with more milk fever $(\mathrm{HR}=8.6)$. All hemorrhages of the sole (scores $=$ 1,2 , and 3 ) were associated with more reproductive hormonal treatments $(\mathrm{HR}=2.3)$. All sole ulcers in firstlactation cows were associated with longer interval from calving to last service $(\mathrm{HR}=0.59)$ and longer calving interval $(\mathrm{HR}=0.61)$, whereas sole ulcers in older cows were associated with longer calving interval $(\mathrm{HR}=0.62)$. All sole ulcers also were associated with more milk fever $(\mathrm{HR}=4.8)$ in all cows. Moderate and severe sole ulcers in older cows were associated with increased interval from calving to first $(\mathrm{HR}=0.35)$ and last $(\mathrm{HR}=0.37)$ service. Moderate and severe whiteline fissures in older cows were associated with in-
\end{abstract}

Received April 19, 2005.

Accepted February 3, 2006.

${ }^{1}$ Corresponding author: aase.sogstad@veths.no creased return rate from previous insemination $(\mathrm{HR}=$ 2.4). Our study shows that claw disorders are associated with poorer reproductive performance and some production diseases.

Key words: claw disorder, reproduction, mastitis, milk fever

\section{INTRODUCTION}

Lameness is an important cause of reduced animal welfare and, along with mastitis and infertility, is an important constraint to the dairy industry (Kossaibati and Esslemont, 1997). Losses are primarily due to prolonged calving intervals, costs of premature culling, reduced yield and quality of milk, and other veterinary costs and treatments by the dairy producer (Enting et al., 1997). Claw disorders cause approximately $90 \%$ of lameness in dairy cattle (Logue et al., 1993; Murray et al., 1996). Cow-level factors thought to be involved in the pathogenesis of claw lesions include parity, stage of lactation, BW, and genetics (Vermunt and Greenough, 1994), whereas herd factors include housing environment, management, and nutrition.

Calving to conception interval, as well as number of services per conception, increased in lame cows (Hernandez et al., 2001). Enting et al. (1997) found that cows with clinical digital disease had greater risk for metabolic disorders. In contrast, Alban (1995) detected no associations between lameness and diseases associated with reproduction, udder, metabolism, or digestion, and others. Fleischer et al. (2001) found no association between any production and claw disease. Furthermore, Hultgren et al. (2004) found no association between mastitis and sole ulcers.

In summary, numerous factors are related to lameness and claw lesions and it is difficult to determine exact cause-and-effect relationships when assessing these disorders and their relation to infertility and disease. Estimating the effect of lesions without any visible lameness is particularly difficult and is rarely described in the literature.

The present study was performed to reveal possible consequences of disorders of the claw and limb to emphasize the importance of preventive measures. The 
aim, therefore, was to identify possible associations of the presence of lameness, lesions at the tarsus, claw shape, and severities of claw lesions recorded at claw trimming with reproductive performance and production diseases such as mastitis, teat injuries, milk fever, clinical ketosis, metritis, and more reproductive hormonal treatments.

\section{MATERIALS AND METHODS}

\section{Selection Procedure}

Herds were stratified based on the 3 most animaldense regions of Norway. Approximately 500 herds with $\geq 15$ cow-years were sampled by computerized systematic assignment from each region by using the Norwegian Dairy Herd Recording System (NDHRS; Østerås, 2003). The total number of herds with $\geq 15$ cow-years within the 3 regions was 4,960. The present study was part of a claw health project using Norwegian cattle in which the main aim was to compare claw health of cows housed in tie stalls and free stalls. Consequently, herds were categorized in 2 housing groups: tie stalls or free stalls. In region 1, 91 herds had freestalls and every third was included. In region 2 , only 25 had free stalls and all were included. In region 3, 84 herds had free stalls and every third was included. One tie stall for every free stall was randomly sampled. One hundred and ninety-three dairy producers were invited to participate in the study. After negative responses, exclusions, and dropouts, 55 tie stalls and 57 free stalls were included. Claw lesions of cows and heifers more than 18 mo of age and of the Norwegian Red cattle breed were recorded. Only females that had calved or were less than $30 \mathrm{~d}$ from first calving were included in this study.

\section{Study Population}

Average (mean \pm SD) number of cows per herd was $25 \pm 10$ and milk production per cow was $6,286 \pm 844$ $\mathrm{kg}$. Approximately $37 \%$ of the energy in the diets came from concentrates, $40 \%$ from grass-silage, $18 \%$ from grass at pasture, and the remainder from other sources. Feeding, housing, and management are described elsewhere in detail (Sogstad et al., 2005b).

Prevalence of lameness and claw lesions in hind claws was: $1.2 \%$ lameness, $26.4 \%$ heel-horn erosions, $16.3 \%$ sole hemorrhages, $10.9 \%$ white line hemorrhages, $2.8 \%$ sole ulcers, and $7.8 \%$ white-line fissures. Most lesions were mild. Prevalence of moderate and severe lesions did not exceed $5 \%$ for any of the lesion categories (Sogstad et al., 2005a).

The original study population contained 2,665 cows. Eighty-two cows were excluded because of missing parity $(\mathrm{n}=8)$, missing identity $(\mathrm{n}=1)$, missing calving date $(n=11)$, or missing peak milk yield $(n=62)$ in the NDHRS database. Of the remaining cows, 1,016 were in their first lactation and 1,567 in second or greater lactation.

\section{Recording of Data}

Thirteen professional claw trimmers attended 2 courses covering claw trimming procedures, diagnosis, recording, and treatment of claw lesions. Individual training was given to each claw trimmer at the initiation of the practical work.

The cows were trimmed and examined once during the period from January 1, 2002 until cows were turned out to pasture during summer. The last herd was visited on June 28. Presence (1) or absence (0) of lameness was assessed when the cow was moved to the trimming chute (Table 1). Peritarsal swellings and wounds were recorded as not present (0), swelling (1), wounded (2), or both swelling and wounded (3). Claw shapes were recorded as normal (0), asymmetric (1), or corkscrewed (2). Claw lesions were diagnosed based on macroscopic examination before and after trimming to the correct claw shape. Trimming technique included leveling the 2 claws, aiming for symmetric bulbs. The axial and abaxial walls were both intended to be parts of the bearing surface and the 2 claws were trimmed flat and balanced with each other. The caudal two-thirds of the axial sole of both claws was dished out. Dermatitis, heel-horn erosions, hemorrhages of the white line and the sole, sole ulcers, and white-line fissures were scored as not present (0), mild (1), moderate (2), or severe (3). Definitions in Table 1 were adapted from Bergsten (2000). The cluster effect within claw trimmer was significant only for heel-horn erosions (Sogstad et al., 2005a).

Artificial insemination and disease events were extracted from the NDHRS. Every cow in Norway has a health card stored at the farm. If diseased, the diagnosis is recorded by the local veterinarian and reported regularly by the farmer or the local advisor, together with all reproductive events, composition and yield of milk, and culling.

Clinical mastitis was defined according to IDF terminology (International Dairy Federation, 1999). Teat injury was defined as any injury or wound affecting the skin or milking procedure. Milk fever was defined as the clinical manifestation of hypocalcemia, characterized by reduced appetite, cold body skin, weakness, and lack of coordination. Most of these cows were recumbent and unable to stand. Reproductive hormonal treatments were defined as single cow therapy of one or more of the following conditions: anestrus (lack of estrus), cystic ovaries, or silent estrus. Clinical ketosis was re- 
Table 1. Definition of lameness and claw lesions recorded at trimming

\begin{tabular}{|c|c|c|}
\hline Lesion & Score & Definition \\
\hline Heel-horn erosion & $\begin{array}{l}1 \\
2 \\
3\end{array}$ & $\begin{array}{l}\text { Slight defects of the horn integrity, pits and small fissures } \\
\text { V-shaped fissures or craters of the heel/bulb not affecting corium } \\
\text { V-shaped profound fissures or craters affecting corium of the heel/bulb }\end{array}$ \\
\hline Hemorrhages of the sole & $\begin{array}{l}1 \\
2 \\
3\end{array}$ & $\begin{array}{l}\text { Slight hemorrhagic discoloration } \\
\text { Moderate hemorrhage on a single spot or several superficial hemorrhages covering }>20 \% \text { of } \\
\text { the sole surface } \\
\text { Profound hemorrhage on a single spot or extensive hemorrhagic discoloration covering }>50 \% \\
\text { of the sole }\end{array}$ \\
\hline White-line fissure & $\begin{array}{l}1 \\
2 \\
3\end{array}$ & $\begin{array}{l}\text { Fissure, which disappear with deep cut beneath normal trimming level } \\
\text { Deep fissure perforating next to the corium of sole or wall } \\
\text { Corium affected with purulent exudates, eventually with necrosis, granulation tissue and } \\
\text { separation of the wall and/or sole }\end{array}$ \\
\hline
\end{tabular}

corded after a positive keto-test in urine or milk, offfeed, and reduced milk production, usually from 10 to 90 DIM.

\section{Data Handling and Statistical Analyses}

The information recorded at the farm was transferred to SAS (Version 8.0; SAS Inst. Inc., Cary, NC) for statistical analyses. Because lameness and all claw lesions occurred at a greater frequency in hind claws than in front claws (Sogstad et al., 2005a), analyses were performed only in hind claws.

Reproductive Performance. Cows were grouped into first and greater lactation groups. Reproductive events during lactation when the claw trimming was performed were included in the hazard risk analyses as a time-dependent variable. When fitting the models, each observation entered the risk set at the time of calving for the lactation when the claw trimming was performed. The risk data were censored at culling date, the next calving date after claw trimming, or at the maximum observation time for each dependent variable if no event occurred before that. In the model of return rate (days from first service to next service) each observation entered the risk set at the time of first service. Associations of lameness, tarsal lesions, claw shapes, and score 1,2, and 3 of each claw lesion were preliminary screened with PROC LIFETEST in SAS generating a Kaplan-Meier plot. The Log-Rank and Wilcoxon tests were used to test for equality over strata. Scores were transformed into dichotomous variables before the final Cox survival analyses. Nonsignificant scores having larger values than the significant one were grouped with the one of significance; preferably combining scores 2 and 3 . In contrast, if score 1 was significant, indicating an association with mild lesions, scores 1,2, and 3 were merged into the same group. For example, if scores 1 and 2 were significant, but not score 3 , score 3 was grouped with 1 and 2 . All single groups had to have a minimum of 5 cows. In this way, we were able to evaluate not only possible associations of lesions being present or not, but also possible cut-off points of subclinical lesions and severity of scores.

Independent variables $(P<0.10)$ from the Log-Rank or Wilcoxon tests were introduced to the Cox regression model (Cox, 1972) using PROC PHREG, accounting for herd as a random effect using a positive stable frailty model available as a SAS macro (Shu and Klein, 1999,, 2005). Independent variables $(P>0.10)$ were removed from the final model one by one by a stepwise backward elimination procedure. The significance level was set at $P<0.05$.

The fit of the models was evaluated by plotting the deviance residuals against the covariates to see if the data were adequately fit by the models (Allison, 2000). To check for proportional hazard assumption the log of the negative log of survival was plotted against time with the most important independent variable as 
strata. These assessments showed no evident violations to the proportional hazards assumption, extreme deviance residuals, or patterns in neither of the models. The final model assessment fit was evaluated by comparing the log likelihood for the full model with the log likelihood of the partial models. The significance of the frailty effect was assessed by likelihood ratio of independence model by H0: Theta = 1. Frailty effect was judged significant when $P<0.05$. The positive frailty model for calving to last service (CLS) in first lactation and for milk fever did not converge and the robust sandwich estimate for the covariance available as standard in SAS was used. Cox regression analyses were run for the time dependent variables days from calving to first service (CFS), last service, calving interval (CINT), and days from first service to next service. Return rate was defined as the proportion of cows that had a subsequent insemination within the same lactation as the claw trimming was performed. The results from the models are presented as hazard ratios (HR) for having a first service, a last service, a new calving, or a next service (return).

The maximum observation time before censoring the data was set to $180 \mathrm{~d}$ for CFS, $270 \mathrm{~d}$ for CLS, $748 \mathrm{~d}$ for CINT, and $120 \mathrm{~d}$ for return rate. Type of stall, DIM at trimming, peak milk yield, and DIM at peak milk yield were included as fixed effects.

Production Diseases. Associations of lameness, tarsal lesions, claw shapes, and claw lesions with mastitis, teat injuries, milk fever, metritis, clinical ketosis, and reproductive hormonal treatments were investigated. Lactation number was treated as a continuous variable and truncated at 4 , because few cows studied were in their fifth or greater lactation. Prescreening survival analyses were performed as for reproductive data and the same procedures of Cox regression analyses using positive frailty model were performed. Each observation entered the risk set at $15 \mathrm{~d}$ before calving for the lactation when the trimming was performed. The data were censored at culling date, next calving date after claw trimming, or at a maximum observation time of 313 DIM for all diseases except milk fever (14 DIM), clinical ketosis (150 DIM), and reproductive hormonal treatments (150 DIM). Only cows that were trimmed before 150 DIM in their second or greater lactation were included in the analyses for milk fever. Type of stall, DIM at trimming, peak milk yield, and DIM at peak milk yield were included as fixed effects. The fit of the models was evaluated as for reproduction. Associations with metritis could not be investigated because of too few observations.

\section{RESULTS}

\section{Reproductive Performance}

During the lactation in which claw trimming was performed, 2,260 cows $(87.5 \%)$ had one or more services.
Averages $( \pm \mathrm{SD})$ for the whole study population were CFS (83 $\pm 38 \mathrm{~d})$; CLS (104 $\pm 57 \mathrm{~d})$; and CINT (381 \pm 52 d). Return rate was $33.0 \%$ for cows that had at least one service. Mean peak daily milk yield was $28.4 \pm 6.4$ $\mathrm{kg}$ at $53 \pm 30$ DIM.

Hazard ratio and confidence intervals (CI) from the Cox regression analyses for reproductive performance are in Tables 2 and 3. The Kaplan-Meier plots for CFS, CLS, CINT, and return rate for sole ulcers during first lactation are in Figure 1. The CFS and return rate are included in Figure 1 to give the overall picture, even though they were not significant in the final model.

Decreased $(P<0.05)$ CFS was associated with moderate and severe hemorrhages of the sole in first-lactation cows, whereas increased $(P<0.05)$ CFS was associated with moderate and severe sole ulcers in older cows. Increased $(P<0.05)$ CLS was associated with moderate and severe sole ulcers in older cows and all levels of sole ulcers in first-lactation cows. Increased $(P<0.05)$ CINT was associated with moderate and severe heelhorn erosions in first-lactation cows and all levels of sole ulcers in first-lactation cows and in older cows. Increased $(P<0.01)$ return rate was associated with moderate and severe white-line fissures in older cows. We found no significant associations with lameness, tarsal lesions, and claw shapes. There was a significant frailty association for CFS, CLS, CINT, but not for return rate.

\section{Production Diseases}

More clinical mastitis was associated with wounds and swellings at the tarsus ( $\mathrm{HR}=4.0 ; \mathrm{CI}=1.4$ to 11.3 ; $P<0.01)$ when adjusted for parity ( $\mathrm{HR}=1.3$; $\mathrm{CI}=1.2$ to $1.5 ; P<0.001$ ). Together, $82.6 \%$ of the observations were censored with a dependent parameter (theta $=$ $0.754 ; \mathrm{SD}=0.041 ; P<0.001)$. More $(P<0.05)$ teat injuries were associated with wounds and swellings at the tarsus ( $\mathrm{HR}=2.5 ; \mathrm{CI}=1.0$ to 6.1 ) when adjusted for stall type (free stall vs. tie stall; $\mathrm{HR}=0.46$; $\mathrm{CI}=$ 0.22 to $0.96 ; P<0.05)$. Together, $98.3 \%$ of the observations were censored with a dependent parameter (theta $=0.917 ; \mathrm{SD}=0.061 ; P<0.05)$; more $(P<0.01)$ milk fever was associated with moderate and severe hemorrhages of the sole ( $\mathrm{HR}=8.6 ; \mathrm{CI}=2.1$ to 34.8 ) and all levels of sole ulcers $(\mathrm{HR}=4.8 ; \mathrm{CI}=1.7$ to 13.8$)$ when adjusted for parity ( $\mathrm{HR}=7.2 ; \mathrm{CI}=3.6$ to $14.7 ; P$ $<0.001$ ) and peak milk yield ( $\mathrm{HR}=1.6$; $\mathrm{CI}=1.3$ to 2.1 ; $P<0.001)$. Overall, $95.1 \%$ of the 815 observations were censored. More $(P<0.01)$ hormonal reproductive treatments were associated with all levels of sole hemorrhages $(\mathrm{HR}=2.3 ; \mathrm{CI}=1.4$ to 3.7$)$, when adjusted for peak milk yield ( $\mathrm{HR}=1.6 ; \mathrm{CI}=1.1$ to $2.4 ; P<0.01$ ). Together, $96.7 \%$ of the observations were censored with 
Table 2. Hazard ratios (HR) and 95\% confidence intervals (CI) from the Cox regression with the positive frailty model or sandwich estimates for traits in first-lactation cows affected by different claw lesion scores ${ }^{1}$

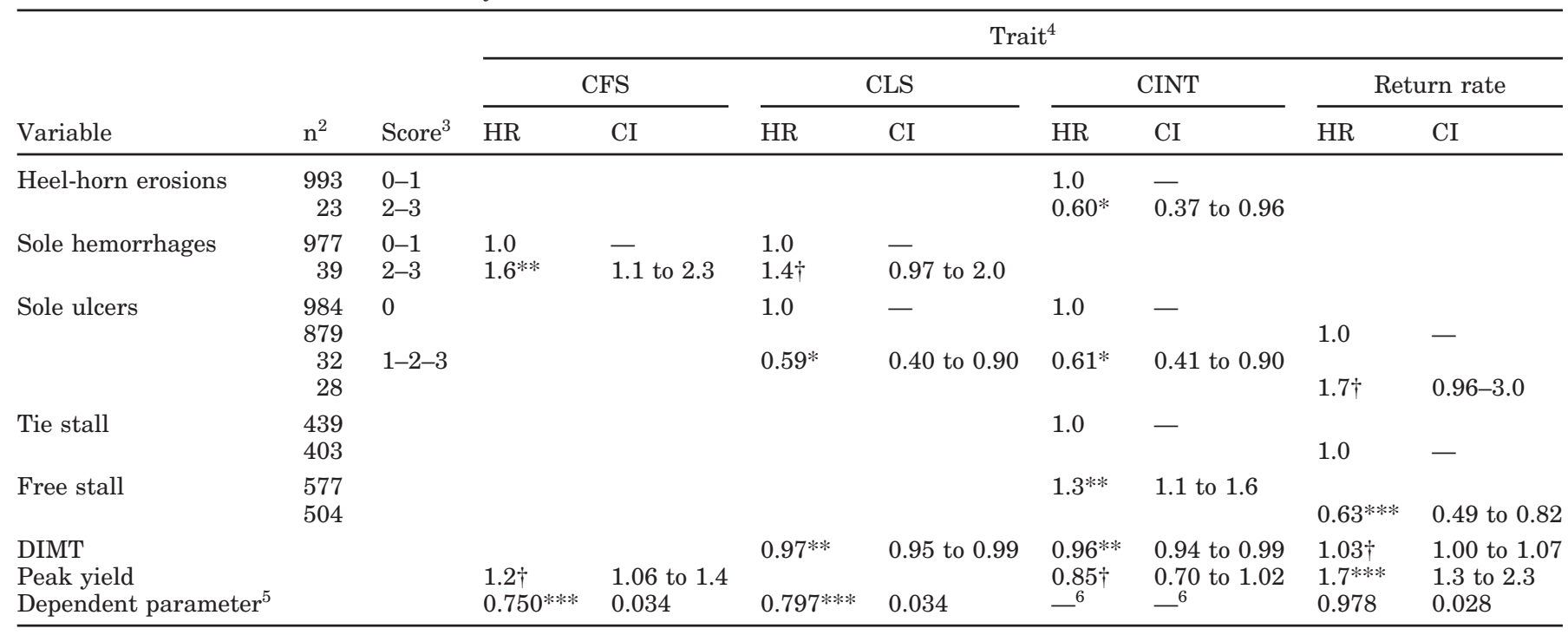

${ }^{1}$ Fixed effects included in the final models were type of stall (tie stall or free stall), DIM at trimming per 30-d increase (DIMT), peak milk yield (per 10-L increase), and DIM at peak milk yield (DIMP). The parameter estimate $(\Theta)$ is given with standard error (SE).

${ }^{2}$ Number of observations $=1,016$ ( $\mathrm{n}=907$ for return rates).

${ }^{3}$ Scores: $0=$ normal, $1=$ mild, $2=$ moderate, and $3=$ severe.

${ }^{4}$ Traits: CFS = time from calving to first service (risk of service); CLS = calving to last service; CINT = calving interval; and return rate (risk of recycling).

${ }^{5}$ Parameter estimate and SE for the dependent parameter (theta) of herd effect.

${ }^{6}$ Model estimated by sandwich method because stable frailty model did not converge.

$\dagger$ Relative $(P<0.10)$ to cows that were not affected by these disorders and scores; $*$ Relative $(P<0.05)$ to cows that were not affected by these disorders and scores; $* *$ Relative $(P<0.01)$ to cows that were not affected by these disorders and scores; $* * *$ Relative $(P<0.001)$ to cows that were not affected by these disorders and scores.

a dependent parameter $($ theta $=0.669 ; \mathrm{SD}=0.076 ; P$ $<0.001$ ).

We found no significant associations with any of the reproductive parameters or production diseases for lameness, claw shapes, and clinical ketosis.

\section{DISCUSSION}

\section{General Discussion}

Study populations, environments, recordings, and statistical methods vary from study to study, making comparisons difficult. Most previous studies relied on various perceptions of dairy producers and veterinary records for the recording of lameness and claw lesions, whereas all available cows in the herd were trimmed and lesions recorded by a professional claw trimmer in our study. Potential bias caused by reluctance or willingness to use proper veterinary care was therefore avoided.

Hultgren et al. (2004) emphasized the importance of recording sole lesions in addition to lameness. A wide spectrum of different severities of claw lesions in this study has not been studied before. Specific prevalence of lameness and claw lesions is discussed in Sogstad et al. (2005a). Prevalence of lameness was less than $2 \%$ and most lesions were mild. Clinical relevance of a mild claw lesion is not fully understood, although these lesions probably predispose more serious lesions and lameness. The multifactorial pathogenesis of claw lesions makes cause-and-effect relationships difficult to determine.

Proportionally more lame cows and cows with moderate and severe claw lesions would have facilitated detection of more reliable associations. Grouping of cows by lactation number also contributed to smaller subgroups and reduced statistical power to detect differences. First-lactation cows are subject to major changes in nutrition, housing, management, and metabolic demands (Logue et al., 1993) and produce less milk than older cows (Sogstad et al., 2005b). Because few cases were detected for each production disease, cows in all lactation groups were included in the same model and effect of lactation number was treated as a continuous fixed effect.

Occurrence of lameness and claw lesions vary depending on the interval since calving. When including 
Table 3. Hazard ratios (HR) and 95\% confidence intervals (CI) from the Cox regression with the positive frailty model or sandwich estimates for traits in second and greater lactation cows affected by different claw lesion scores ${ }^{1}$

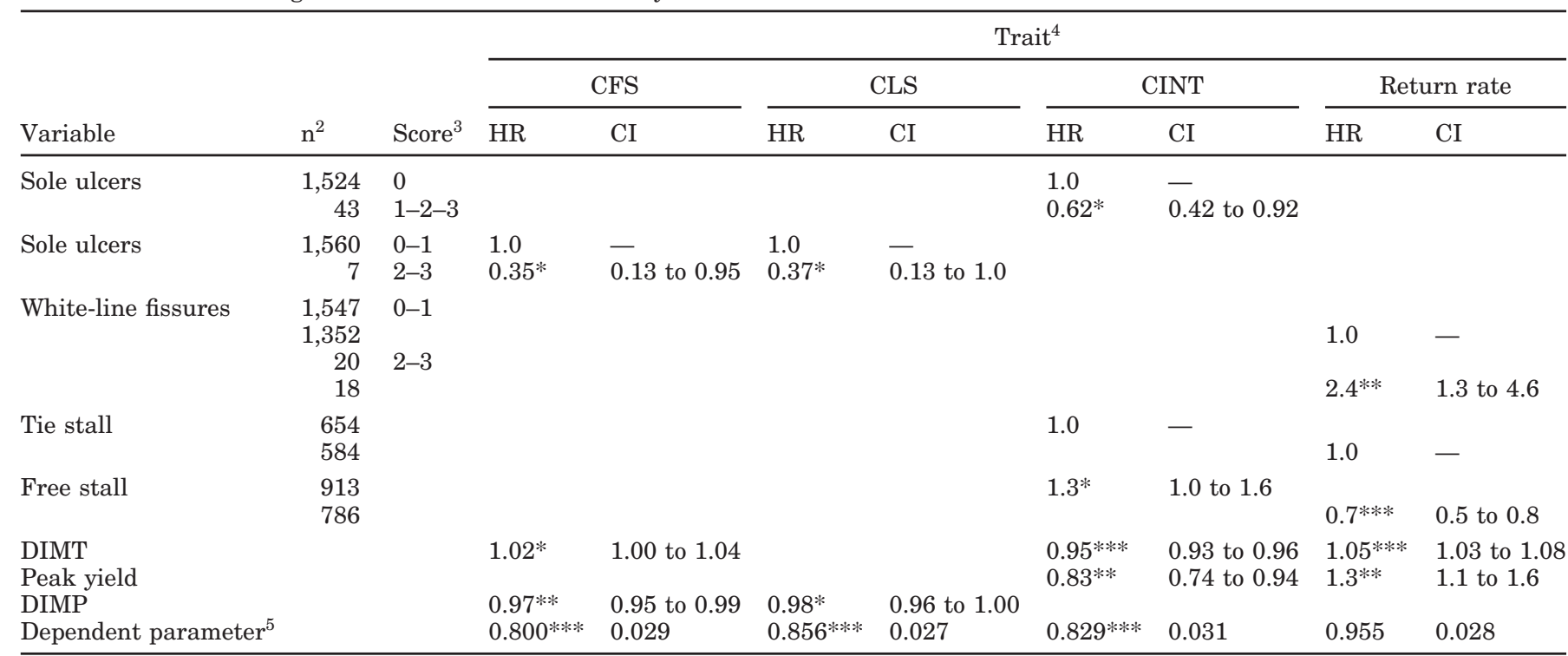

${ }^{1}$ Fixed effects included in the final models were type of stall (tie stall or free stall), DIM at trimming per 30-d increase (DIMT), peak milk yield (per 10-L increase) and DIM at peak milk yield (DIMP). The parameter estimate (theta) is given with standard error (SE).

${ }^{2}$ No. of observations $=1,567$ ( $\mathrm{n}=1,370$ for return rates $)$.

${ }^{3}$ Scores: $0=$ normal, $1=$ mild, $2=$ moderate, and $3=$ severe.

${ }^{4}$ Traits: CFS = time from calving to first service (risk of service); CLS = calving to last service; CINT = calving interval; and return rate (risk of recycling).

${ }^{5}$ Parameter estimate and SE for the dependent parameter (theta) of herd effect.

$\dagger$ Relative $(P<0.10)$ to cows that were not affected by these disorders and scores; *Relative $(P<0.05)$ to cows that were not affected by these disorders and scores; **Relative $(P<0.01)$ to cows that were not affected by these disorders and scores; ***Relative $(P<0.001)$ to cows that were not affected by these disorders and scores.

censored data in the analyses, overestimating relationships between a lesion and CINT, for example, is avoided because of a longer period at risk for cows having a prolonged CINT. Further, without applying survival analyses, cows with a disorder of the limb or claw that were culled before claw trimming because of reproductive problems or production diseases might have underestimated those relationships (Gasqui and Barnouin, 2003).

The cluster effect within herd was significant for all hind claw lesions, but was most marked for heel-horn erosions in our study (Sogstad et al., 2005a). The cluster effect within claw trimmer was only significant for heelhorn erosions, indicating that the effect of claw trimmer did not influence the results to a large extent. Possible errors caused by differences in recording between claw trimmers are discussed in more detail elsewhere (Sogstad et al., 2005a).

Correctly performed claw trimming has preventive and curative effects on claw lesions (Manske et al., 2002) and might have caused underestimation bias. Mild and moderate cases can be prevented from further deterioration, and therefore not affect reproductive per- formance and production diseases, whereas severe cases could heal.

Grouping of scores to dichotomous variables makes the models more robust because of more observations in each group. Because few cows had severe cases (score $=3$ ), we preferred to group together moderate and severe cases. If score 1 was significant by LogRank or Wilcoxon, the significance also was assessed by considering whether a prejudged causality association could be shown even for mild scores of that particular lesion. For mild sole ulcers, the corium is exposed and an effect is quite likely (Table 1). When associations of different lesions with different reproductive parameters and production diseases are analyzed, a risk exists that significance can occur by chance. Thirteen different significant associations were found in total, however, which is much more than expected by chance. Care should be taken when interpreting causal relationships, especially when the link between the lesions and reproduction performance or disease is difficult to explain. Management factors such as nutrition also complicate the picture by influencing both the independent and the dependent variables. 

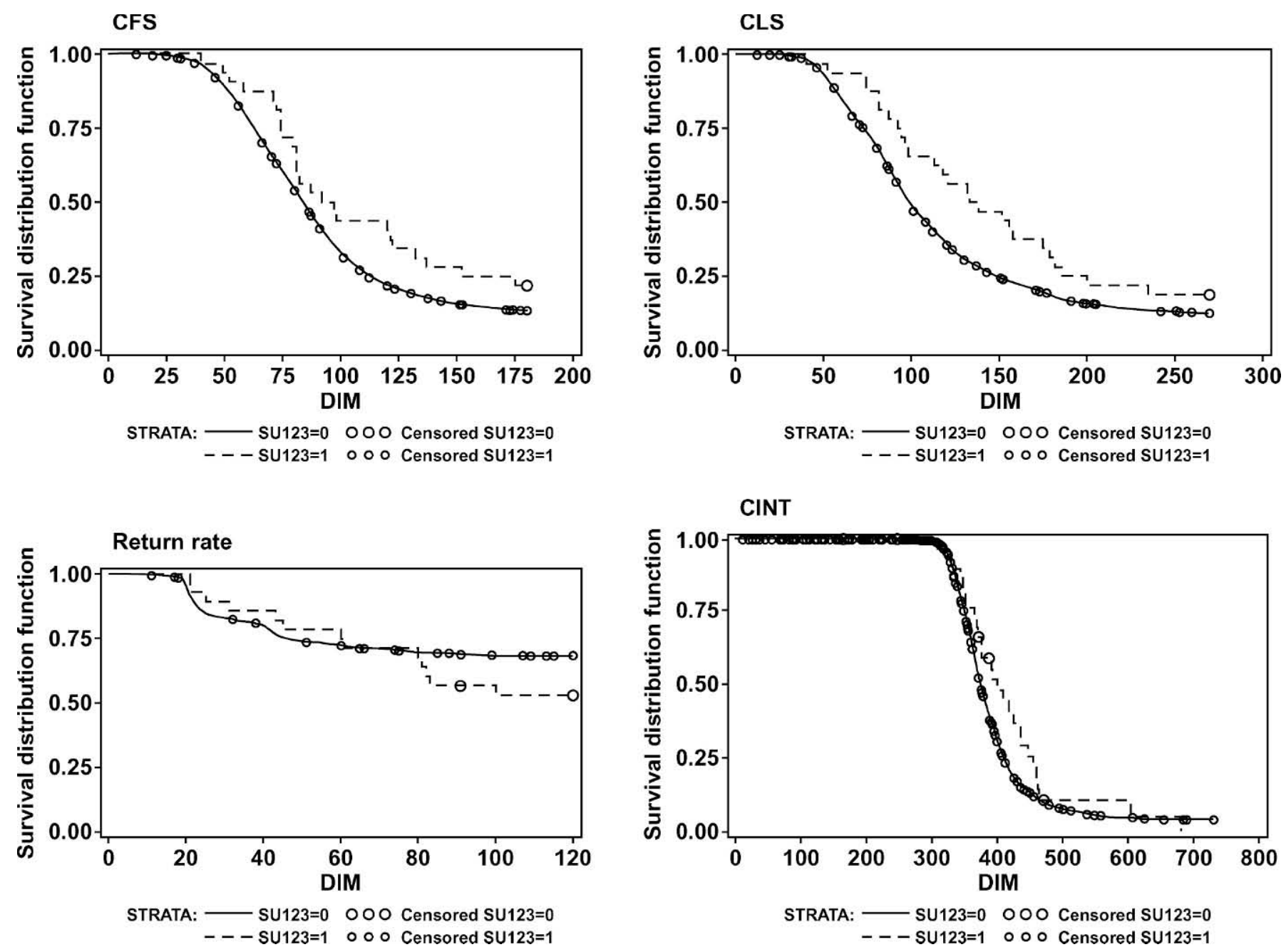

Figure 1. Kaplan-Meier plots showing the time interval from calving to first service (CFS), calving to last service (CLS), return rate, and calving interval (CINT) for first-lactation cows with all levels of sole ulcers (SU123 = 1) or without sole ulcers $($ SU123 = 0 ).

In short, numerous factors influenced the dependent variables in our study and the limited power makes interpretation of the various associations somewhat tentative. We believe, however, that the associations presented herein are important and warrant further studies.

\section{Reproductive Performance}

Most researchers have studied the effect of lameness on fertility and reproductive performance, without going into detail on each lameness diagnosis. Enting et al. (1997) found a longer CINT for cows with clinical digital diseases, whereas Collick et al. (1989) found that lame cows experienced a longer CFS, a longer interval from calving to conception, and needed more services per conception than nonlame cows. Hernandez et al. (2001) found that lame cows having claw lesions were
0.52 times as likely to conceive as healthy cows. Garbarino et al. (2005) found that severe (and moderate) cases of lameness were associated with delayed ovarian activity in Holstein cows, whereas no effect of mild lameness was revealed. We did not find associations between lameness and reproductive performance, possibly because of a small number of lame cows. We can speculate that mild and moderate cases of lameness have been overlooked.

Moderate and severe heel-horn erosions in first-lactation cows were associated with longer CINT. Severe erosions affect the corium (Bergsten, 2000) and cause pain. Cows with tender feet are more reluctant to walk and likely eat less than other cows. These cows are also more likely to show reduced estrual activity.

First-lactation cows in this study had more hemorrhages than older cows (Sogstad et al., 2005b). Cows fed high concentrate diets are more prone to hemorrhages 
(Logue et al., 1993) and hemorrhages are considered to be a consequence of vascular damage in connection with acute, subacute, or subclinical laminitis, or claw horn disruption as some authors prefer to describe it (Hoblet and Weiss, 2001). Shorter CFS in first-lactation cows having moderate and severe sole hemorrhages might be due to these cows being well fed.

Association between all levels of sole-ulcer severities and longer CINT corroborates earlier findings (Hultgren et al., 2004), in which these associations of sole ulcers and first-service conception rate were reported. Sole ulcers in our study are a clear cause of lameness (Sogstad et al., 2005a). It has been shown that lame cows lose more BW and spend less time eating than nonlame cows (Hassall et al., 1993). Cows with sole ulcers might consequently experience more prolonged negative energy balance and onset of postpartum estrous cycles (Staples et al., 1990). Hultgren et al. (2004) suggested that pain-induced stress (Dobson and Smith, 2000) or concurrent effects of endotoxins on ovulation or blood concentrations of progesterone (Suzuki et al., 2001) might be involved in poorer reproductive performance. Expression of estrus is likely more difficult when cows have tender feet. Melendez et al. (2002) found that when most lameness was related to subclinical laminitis, lameness was associated with poorer conception rates at first service, a greater incidence of ovarian cysts, and poorer pregnancy rates. A larger increase in the interval from calving to conception than for CFS (Collick et al., 1989) suggested that the main effect of lameness was on conception or the maintenance of pregnancy. Prolonged CFS and CLS for cows having sole ulcers in our study also indicates that the association might be related to a delayed onset of postpartum estrous cycles or a decreased conception/maintenance rate, or both.

Moderate and severe white-line fissures in older cows were associated with increased return rate, caused lameness in this population (Sogstad et al., 2005a), and are likely to decrease reproductive performance by the same mechanisms as described for sole ulcers.

\section{Production Diseases}

Most other studies have pooled all digital disorders and associated these with the total number of disease treatments or disease complexes. Enting et al. (1997) found that cows with clinical digital diseases had more risk of metabolic disorders. Gynecological disorders and retained placenta was slightly related to digital disorders, whereas no relationship was found between the incidence of clinical digital diseases and feeding disorders. Several studies did not detect associations between lameness or claw lesions and production diseases
(Enevoldsen et al., 1991; Alban, 1995; Fleischer et al., 2001).

When both a wound and a swelling are present at the tarsus, a painful peritarsal infection often ensues. Association between lesions at the tarsus and teat injuries in cows in our study might be explained by their difficulty in getting up from recumbence or lying down and associated teat injuries. Poorly maintained claws and lameness are risk factors for teat injuries, which in turn lead to subclinical or clinical mastitis (Østerås and Lund, 1988; Rajala-Schultz and Gröhn, 1999). Association between wounds and swellings at the tarsus and clinical mastitis in the present study also might be related to cow comfort, management, and hygiene. Bacterial contamination of the bedding might be a link between infections of the tarsus and the udder.

Mechanical pressure is an important factor in the pathogenesis of subclinical laminitis and claw horn disruption (Bergsten and Frank, 1996). Association between moderate and severe sole hemorrhages and milk fever might occur because some cows struggle when rising and lying down, resulting in uneven or increased mechanical pressure to the claws. Mülling et al. (1999) reported that differentiating epidermal cells are sensitive to changes in plasma calcium concentrations, possibly causing formation of dyskeratotic horn. Calcium is involved in hemostasis and we speculate that hypocalcemia may contribute to development of hemorrhages (Hawiger et al., 1994). Cows with tender feet are more likely to lie down when they get weak because of hypocalcemia than those with sound claws.

Hormonal treatments in Norway are almost exclusively aimed at treating anestrus or silent estrus in single cows. Herds are relatively small and the focus has been and still is on single-cow estrus detection, thus making associations between hormonal treatments and claw lesions relevant. Cows fed high concentrate diets are more prone to hemorrhages (Logue et al., 1993) around the time of calving and fat cows are more likely than thin cows to experience a negative energy balance after calving. Negative energy balance is known to delay onset of postpartum estrous cycles (Staples et al., 1990) and might involve hormonal treatments, possibly explaining the association between all severities of sole hemorrhages and more hormonal reproductive treatments. Hormones such as relaxin are thought to play an important role in the softening of the connective tissue supports the third phalanx and thereby the development of claw lesions around calving (Lischer and Ossent, 2002; Tarlton et al., 2002).

Association between all severities of sole ulcers and milk fever might be explained by the same mechanisms as for sole hemorrhages. Vaarst et al. (1998) found previous disease treatments, udder-related disorders, and 
disorders other than reproductive problems were positively associated with the occurrence of sole ulcers. Limited numbers of recorded sole ulcers in our study might have masked relations between sole ulcers and other diseases. The hazard ratios and $95 \%$ confidence intervals were relatively large for the production diseases, indicating that the results are unreliable because of few cases in each group.

\section{CONCLUSIONS}

Our study showed that wounds and swellings at the tarsus and claw lesions such as heel-horn erosions, sole hemorrhages and ulcers, and white-line fissures were associated with poorer reproductive performance and increased occurrence of mastitis, teat injuries, milk fever, and more hormonal treatments. Preventive measures, appropriate actions, and early detection of claw and limb disorders could be important to improve reproductive performance and limit occurrence of some production diseases.

\section{ACKNOWLEDGMENTS}

The authors thank the participating claw trimmers and dairy farmers, Kerstin Plym-Forshell, who was a main promoter in the planning stage of the study, and Arne Ola Refsdal for his comments. The study was funded by TINE Norwegian Dairies BA, GENO Breeding and A.I. Association, Norwegian Meat Research Centre, and The Research Council of Norway. Access to production and health data was given by the Norwegian Dairy Herd Recording System and the Norwegian Cattle Health Services in agreement number 6/2001 (19.09.2001).

\section{REFERENCES}

Alban, L. 1995. Lameness in Danish dairy cows: Frequency and possible risk factors. Prev. Vet. Med. 22:213-225.

Allison, P. D. 2000. Survival analysis using the SAS system: A practical guide. SAS Institute Inc., Cary, NC.

Bergsten, C. 2000. Workshop report about the documentation of claw diseases. Part 2. Pages 12-16 in Proc.11th Int. Symp. Disorders of the Ruminant Digit. C. M. Mortellaro, L. Vecchis, A. De. Brizzi, ed. Parma, Italy.

Bergsten, C., and B. Frank. 1996. Sole haemorrhages in tied primiparous cows as an indicator of periparturient laminitis: Effects of diet, flooring and season. Acta Vet. Scand. 37:395-408.

Collick, D. W., W. R. Ward, and H. Dobson. 1989. Associations between types of lameness and fertility. Vet. Rec. 125:103-106.

Cox, D. R. 1972. Regression models with life-tables (with discussion). J. R. Stat. Soc. Ser. B. 34:187-220.

Dobson, H., and R. F. Smith. 2000. What is stress and how does it affect reproduction? Anim. Reprod. Sci. 60-61:743-752.

Enevoldsen, C., Y. T. Grohn, and I. Thysen. 1991. Sole ulcers in dairy cattle: Associations with season, cow characteristics, disease, and production. J. Dairy Sci. 74:1294-1298.

Enting, H., D. Kooij, A. A. Dijkhuizen, R. B. M. Huirne, and E. N. Noordhuizen-Stassen. 1997. Economic losses due to clinical lameness in dairy cattle. Livest. Prod. Sci. 49:259-267.
Fleischer, P., M. Metzner, M. Hoedemaker, S. Slosarkova, and M. Skrivanek. 2001. Clinical disorders in Holstein cows: Incidence and associations among lactational risk factors. Acta Vet. (Brno) 70:157-165.

Garbarino, E. J., J. A. Hernandez, J. K. Shearer, C. A. Risco, and W. W. Thatcher. 2005. Effect of lameness on ovarian activity in postpartum Holstein cows. J. Dairy Sci. 87:4123-4131.

Gasqui, P., and J. Barnouin. 2003. Statistical modelling for clinical mastitis in the dairy cow: Problems and solutions. Vet. Res. 34:493-505.

Hawiger, J., L. F. Brass, and E. W. Salzman. 1994. Signal transduction and intracellular regulatory processes in platelets. Page 603 in Hemostasis and thrombosis: Basic principles and clinical practice. 3rd ed. R. W. Colman, J. Hirsh, V. J. Marder, and E. W. Salzman, ed. J. B. Lippincott Company, Philadelphia, PA.

Hassall, S. A., W. R. Ward, and R. D. Murray. 1993. Effects of lameness on the behaviour of cows during the summer. Vet. Rec. 132:578-580.

Hernandez, J., J. K. Shearer, and D. W. Webb. 2001. Effect of lameness on the calving-to-conception interval in dairy cows. J. Am. Vet. Med. Assoc. 218:1611-1614.

Hoblet, K. H., and W. Weiss. 2001. Metabolic hoof horn disease. Claw horn disruption. Vet. Clin. North Am. Food Anim. Pract. 17:111-127.

Hultgren, J., T. Manske, and C. Bergsten. 2004. Associations of sole ulcer at claw trimming with reproductive performance, udder health, milk yield and culling in Swedish dairy cattle. Prev. Vet. Med. 62:233-251.

International Dairy Federation (IDF). 1999. Suggested interpretation of mastitis terminology. Bulletin No 338/1999. IDF, Brussels, Belgium.

Kossaibati, M. A., and R. J. Esslemont. 1997. The costs of production diseases in dairy herds in England. Vet. J. 154:41-51.

Lischer, C. J., and P. Ossent. 2002. Pathogenesis of sole lesions attributed to laminitis in cattle. Pages 82-89 in Proc. 12th Int. Symp. Lameness in Ruminants. J. K. Shearer, ed. Orlando, FL.

Logue, D. N., J. Offer, and S. A. Kempson. 1993. Lameness in dairy cattle. Irish Vet. J. 46:47-58

Manske, T., J. Hultgren, and C. Bergsten. 2002. The effect of claw trimming on the hoof health of Swedish dairy cattle. Prev. Vet. Med. 54:113-129.

Melendez, P., J. Bartolome, and A. Donovan. 2002. Relationship between lameness, ovarian cysts and fertility in Holstein cows. Pages 339-342 in Proc. 12th Int. Symp. Lameness in Ruminants. J. K. Shearer, ed. Orlando, FL.

Mülling, C., H. Bragulla, S. Reese, K. D. Budras, and W. Steinberg. 1999. How structures in bovine hoof epidermis are influenced by nutritional factors. Anat. Hist. Embryol. 28:103-108.

Murray, R. D., D. Y. Downham, M. J. Clarkson, W. B. Faull, J. W. Hughes, F. J. Manson, J. B. Meritt, W. B. Russel, J. E. Sutherst, and W. R. Ward. 1996. Epidemiology of lameness in dairy cattle: Description and analysis of foot lesions. Vet. Rec. 138:586-591.

Østerås, O. 2003. The health card system. Annual report, 2002. Norsk Veterinærtidsskrift 115:431-442.

Østerås, O., and A. Lund. 1988. Epidemiological analyses of the associations between bovine udder health and housing. Prev. Vet. Med. 6:79-90.

Rajala-Schultz, P. J., and Y. T. Gröhn. 1999. Culling of dairy cows. Part 1. Effects of diseases on culling in Finnish Ayrshire cows. Prev. Vet. Med. 41:195-208.

Shu, Y., and J. P. Klein. 1999. A SAS macro for the positive stable frailty model. Page 47-52 in Proc. Statistical Computing Section. Am. Stat. Assoc.

Shu, Y., and J. P. Klein. A SAS Macro for the positive stable frailty model. Available http://www.biostat.mcw.edu/software/SoftMenu.html Accessed Sept. 1, 2005.

Sogstad, Å. M., T. Fjeldaas, and O. Østerås. 2005a. Prevalence of claw lesions in Norwegian dairy cattle housed in tie stalls and free stalls. Prev. Vet. Med. 70:191-209.

Sogstad, A. M., T. Fjeldaas, and O. Østerås. 2005b. Lameness and claw lesions of the Norwegian Red dairy cattle housed in free 
stalls in relation to environment, parity and stage of lactation. Acta Vet. Scand. 4:203-217.

Staples, C. R., W. W. Thatcher, and J. H. Clark. 1990. Relationship between ovarian activity and energy status during the early postpartum period of high producing dairy cows. J. Dairy Sci. 73:938-947.

Suzuki, C., K. Yoshioks, S. Iwamura, and H. Hirose. 2001. Endotoxin induces delayed ovulation following endocrine aberration during the proestrous phase in Holstein heifers. Domest. Anim. Endocrinol. 20:267-278.
Tarlton, J. F., D. E. Holah, K. M. Evans, S. Jones, G. R. Pearson, and A. J. F. Webster. 2002. Biochemical and histopathological changes in the support structures of bovine hooves around the time of first calving. Vet. J. 163:196-204.

Vaarst, M., J. Hindhede, and C. Enevoldsen. 1998. Sole disorders in conventionally managed and organic dairy herds using different housing systems. J. Dairy Res. 65:175-186.

Vermunt, J. J., and P. R. Greenough. 1994. Predisposing factors of laminitis in cattle. Br. Vet. J. 150:151-164. 